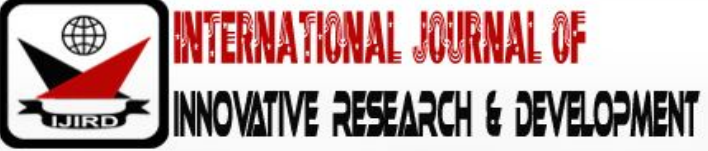

ISSN 2278 - 0211 (Online)

\section{Problem Based Learning for Fourth Year Medical Students in Fayoum Governorate, Egypt}

\author{
Marwa Ali Mwaheb \\ Lecturer, Department of Forensic Medicine and Clinical Toxicology, Fayoum University, Egypt
}

\begin{abstract}
:
Background: Problem based learning (PBL) consider that the most significant development in education over the past five decades. It has been boosted by the curriculum of choice, and since its introduction in the 1960's, has been vastly adopted by many medical and dental schools. Objectives: The aim of this research was to compare the development and recollection of knowledge in the medical sciences between students on the traditional and reformed undergraduate medical curricula, respectively.

Methods: For each medical student has taken, The Progress Test Medizin (PTM), relative frequencies of correct answers were computed for basic sciences items only and for the whole curriculum. Frequencies were averaged and grouped by semester and curriculum. Analyses of variance (ANOVAs) were performed at all measurement points with a Bonferroni-corrected pvalue at the level of $\mathrm{p}<0.005$. Eta-squared ( $\mathrm{g} 2$ ) was used to classify effect size.

Results: The current study occurs on 80 fourth year medical students divided into two rounds. First round study by the traditional medical curriculum (lecture group) whiles the second round study by the reformed medical curriculum (problem learning group). The present study shows that there is statistically significant difference with p-value $\varangle 0.05$ between different topics among lecture teaching method with the lowest score given for identification topic and the highest core for death topic; which indicated that lecture methods not suits some topics as identification topic

Conclusion: Proceed testing as a longitudinal method allows us to better understand the development of knowledge during formal undergraduate education. The main difference between traditional and problem-based medical education demonstrate to be induced by the high-stakes national examination undertaken in the traditional course.
\end{abstract}

Keywords: Education, problem based learning, medical students

\section{Introduction}

Problem-based learning (PBL) is a widely used method that uses cases (problems), to push learning and engage student's discussion in small groups. Students in PBL tutorials learn cooperatively by integrating knowledge, solving and explaining the problem, and identifying their learning needs. During the learning process, student's interaction and group function are central to the different phases of the PBL tutorials (1). Therefore, PBL tutorials aim at retrievingtraditional teacher-student interactions towards more active student-student interactions. Facilitators (tutors) in PBL coach students with suggestions for further study or explanations but do not necessarily allocate specific predetermined task activities (2-4).

Students' interactions promote the critical thinking process and push students to explore deep learning. Therefore, deep learning is enforced when students become responsible for their own learning and use critical analyses effectively as part of their learning process (5). However, PBL is a student centred oncoming to teaching and learning in which students are exposed to trigger learning materials based on 'real life problems' (6). Students work in small groups to explore and examine the issues that arise from the learning materials.

Individual students address their own learning needs and are also tasked with examining some of the specific issues that arise. A formal review of progress takes place before the collated information is fed back to the group. This process of learning is active, self-directed and cyclical (7). The involvement of the lecturer in this process is essentially that of facilitator. There are a whole series of benefits associated with PBL. These include the idea that PBL enhance deeper learning, in which there is genuine understanding of an issue as well as the reflective application of interpersonal skills and/ or knowledge (7)

According to the Problem-based Learning Special Interest Group (2009), research into PBL occupies four main areas: curriculum design, facilitation, effectiveness of learning, and student experience, which is the most researched category. This report, however, suggests that the magnitude of this work is focussed on evaluating particular modules or units that use PBL rather than whole courses or programmes (8) 


\subsection{Aim}

This study aimed to evaluate the experiences of underground students undertaking a problem bases learning based underground programme and explore the validity of these findings through comparison with previously published reports.

\section{Material and Methods}

The current study occurs on 80 fourth year medical students divided into two rounds. First round study by the traditional medical curriculum (lecture group) whiles the second round study by the reformed medical curriculum (problem learning group) from January2018 to April2018 were included. Medicine College in Fayoum Governorate, The Progress Test Medizin (PTM) results of tests taken. For each student and each single test, the relative frequencies of correct answers were computed for questions on 4 topics in forensic medicine and clinical toxicology, (Identification, Death and post mortem changes, volatile gases e.g. Co, cyanide)as well as for the complete test. The respective relative frequencies were averaged and grouped by semester and curriculum.

The Progress Test Medizin PTM [Progress Test in Medicine]), administered for four months, contains 20 multiplechoice questions (MCQs), formulated as single best-answer items. The PTM is a formative assessment tool on which no pass / fail decision is made. It is not intended to trigger extensive test preparation, but to measure knowledge that is available spontaneously. It is nevertheless mandatory for students to complete the test each semester under regular examination conditions ${ }^{(\mathbf{9})}$.

\subsection{The Traditional Medical Curriculum (TMC)}

The traditional curriculum has been developed on the assumption that medical knowledge can be best acquired when each subject is presented by experts in a systematic blocked format. After each teaching block, summative examinations written by faculty staff must be passed. The system is entirely subject-based and focuses almost exclusively on the basic forensic medicine and clinical toxicology during the first 2 months. After students have finished a subject and passed the subsequent examination, it will not be taught again.

\subsection{The Reformed Medical Curriculum (RMC)}

By contrast, the RMC was established based upon constructivist learning theory, with PBL as its central teaching method on Problem-based learning sessions in second 2 months. Teaching is meant to present aproblem (that evokes a cognitive conflict which can only be solved by learning the missing contents). The teacher's role is to present the problem and to use hisor her expertise to enable the students to solve it. According to problem-based approaches to learning have a long history of advocating experience-based education (10).

\section{Statistical Analysis}

- Data were collected and coded to facilitate data manipulation and double entered into Microsoft Access and data analysis was performed using SPSS software version 18 in windows 7 (IBM, Chicago, IL, USA).

- Simple descriptive analysis in the form of arithmetic means as central tendency measurement, standard deviations as measure of dispersion for quantitative parametric data, and inferential statistic test:

\subsection{For Quantitative Parametric Data}

- In-depended student t-Test used to compare measures of two independent groups of quantitative data.

- One way ANOVA test in comparing more than two independent groups of quantitative data with benferroni Post-HOC to test significance between each two groups.

- The P-value $\leq .05$ was considered the cut-off value for significance.

\section{Results}

The current study occurs on 80 fourth year medical students divided into two rounds. First round study by the traditional medical curriculum (lecture group) whiles the second round study by the reformed medical curriculum (problem learning group). Table (1) illustrates that there is statistically significant difference with p-value $<0.05$ between different topics among lecture teaching method with the lowest score given for identification topic and the highest core for death topic; which indicated that lecture methods not suits some topics as identification topic. Also, table (1)demonstrates that there is no statistically significant difference with p-value $>0.05$ between different topics among problem solving teaching method, which indicated problem solving method suits all topic simultaneously. 


\begin{tabular}{|c|c|c|c|c|}
\hline \multirow{2}{*}{ Variables } & \multicolumn{2}{|c|}{ Problem Solving Group } & \multicolumn{2}{c|}{ Lecture group } \\
\cline { 2 - 5 } & Mean & SD & Mean & SD \\
\hline Identification & 2.73 & 1.4 & $\mathbf{2 . 8 7}$ & 0.86 \\
\hline Death & 3.27 & 1.2 & 3.8 & 1.1 \\
\hline CO\& cyanide & 2.97 & 1.2 & 3.2 & 1.2 \\
\hline p-value & \multicolumn{2}{|c|}{0.3} & \multicolumn{2}{c|}{$0.003^{a *}$} \\
& \multicolumn{2}{c}{$0.6^{\mathrm{b}}$} \\
& \multicolumn{2}{c}{$0.09^{\mathrm{c}}$} \\
\hline
\end{tabular}

Table 1: Comparisons of Knowledge Score of Different

Topics in Each Teaching Methods

- Statistical significance difference between identification and death topics

- Statistical significance difference between identification and co\& cyanic topics

- Statistical significance difference between death and CO \& cyanide topics

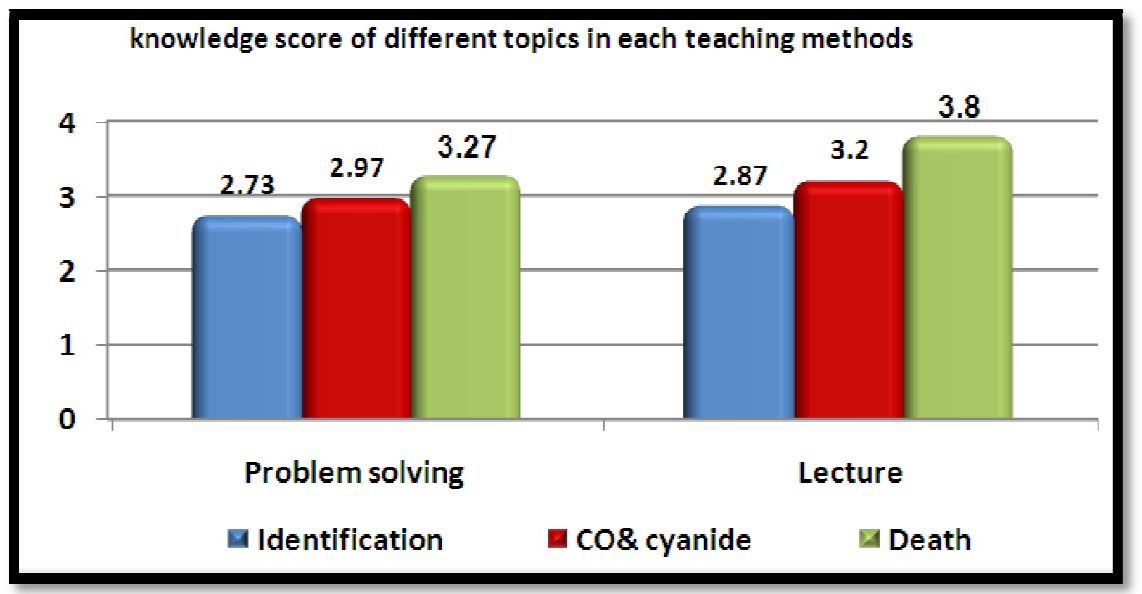

Figure 1: Scoring of Different Topics in Different Teaching Method

Table(2) recorded that there is no statistically significant difference with $p$-value $>0.05$ between two teaching methods as regards to knowledge score totally and in each topic; which indicated both methods had same effect on knowledge score.

\begin{tabular}{|c|c|c|c|c|c|}
\hline \multirow{2}{*}{ Variables } & \multicolumn{2}{|c|}{ Problem Group } & \multicolumn{2}{c|}{ Lecture Group } & \multirow{2}{*}{ p-Value } \\
\cline { 2 - 5 } & Mean & SD & Mean & SD & \\
\hline Identification & 2.73 & 1.4 & 2.87 & 0.86 & 0.6 \\
\hline Death & 3.27 & 1.2 & 3.8 & 1.1 & 0.07 \\
\hline CO\& cyanide & 2.97 & 1.2 & 3.2 & 1.2 & 0.5 \\
\hline Total score & 8.97 & 2.3 & 9.87 & 1.9 & 0.1 \\
\hline
\end{tabular}

Table 2: Comparisons of Knowledge Score between Different Teaching Methods

\section{Discussion}

PBL challenges students to organise their own acquisition of knowledge and to intensify this knowledge through the exchanges in the group. This can lead to learners being dissatisfied with their learning outcomes and PBL causing frustration. Thus, the success of PBL is greatly influenced by the teaching skills of the tutor (11)'(12)

In this study, where two curricula run in parallel and students are randomised to each, offers a solid basis from which to collect robust data for curricular comparisons. However, it should be acknowledged that there may be differences in preferred learning styles and ability to answer MCQs between the students in the two groups. The development of medical knowledge during undergraduate medical education does not differ strongly between the traditional and the PBL curriculum, but students on the TMC show greater difficulty in answering PTM items correctly during the first twomonths ${ }^{(\mathbf{9})}$.

The teaching approach on the TMC is reflected in the rapid growth in knowledge, which declines after the bulk of learning and assessment is completed, whereas the RMC philosophy seems to lead to far more continuous growth. This conflicts with the observation of other study (13), of a strong correlation between basic sciences knowledge in traditional curriculum students and time spent acquiring those subjects.

This disagree with the results of this research because documented that the traditional curriculum affective in identification topic while problem based learning more effective in death and post-mortem change, this mean the problem based learning affective in some topics and not effect for other topics in forensic medicine and clinical toxicology approaches. 


\section{Conclusion}

The results of this study propose that there is no systematic difference between a traditional and a problem-based curriculum in terms of the assimilation of overall medical information. Future research in this area should include more medical schools with differing curriculum in command to find out whether other types of curriculum, such as competencebased approaches, could be have more effect on the development and retention of knowledge.

\section{References}

i. Schmidt HG, Rotgans JI and Yew EH: He process of problem-based learning: what works and why. Med Educ,2011. 45: 792-806.

ii. Colliver JA:Effectiveness of problem-based learning curricula: research and theory. Acad Med, 2000. 75: 259-266.

iii. Schmidt HG, van der Molen HT, Te Winkel WWR and Wijnen

iv. WHFW;Constructivist, problem-based learning does not work: a meta-analysis of curricular comparisons involving a single medical school. Educ Psychol, 2009. 44: 227-249.

v. Albanese MA and Mitchell S: Problem-based learning: a review of literature on its outcomes and implementation issues. Acad Med, 1993. 68: 52-81.

vi. Mergendoller JR, Maxwell NL and Bellisimo Y:The effectiveness of Problem-based instruction: a comparative study of instructionalmethods and student characteristics. IJPBL .2006: 1:2.

vii. Matheson, R. and Haas, B: Exploring the foundations forproblem-based learning. In: T. Clouston, L. Westcott, S.Whitcombe, J. Riley \& R. Matheson (Eds). Problem-Based-Learning in Health and Social Care.2010 (pp. 9-24). Chichester: Wiley-Blackwell.

viii. Westcott, L., Seymour, A. and Roberts, S: Developing problem-based learning curricula in health and social care. In: T. Clouston, L. Westcott, S. Whitcombe, J. Riley \& R. Matheson (Eds). Problem-Based-Learning in Health and Social Care. 2010(pp. 35-50).

ix. Problem-based Learning Special Interest Group:Evaluating problem-based learning: A toolkit for lecturers and practitioners2009

x. Zineb Nouns, Stefan Schauber, Claudia Witt, Halina Kingreen and Katrin Schu"ttpelz-Brauns.:Development of knowledge in basic sciences: a comparison of two medical curricula. Medical Education, 2012.46: 1206-1214

xi. Hmelo-Silver CE:Problem-based learning: what and how do students learn? Educ Psychol.2004;16 (3):235-66.

xii. Lekalakala-Mokgele E.: Facilitation in problem-based learning: experiencing the locus of control. Nurse Educ Today;2010.30(7):638-642.

xiii. Gingerich A, Mader H and Payne GW.:Problem-based learning tutors within medical curricula: an interprofessional analysis. J Interprof Care.2012;26(1):69-70.

xiv. Vernon DT, Blake RL:Does problem-based learning work? A meta-analysis of evaluative research. Acad Med ,1993;68:550-63 